\title{
Analysis of magnetotelluric data along the Lithoprobe seismic line 21 in the Blake River Group, Abitibi, Canada
}

\author{
Benoit Tournerie and Michel Chouteau \\ École Polytechnique de Montréal, Québec, H3C $3 A 7$ Canada \\ (Received December 13, 2000; Revised November 2, 2001; Accepted December 3, 2001)
}

\begin{abstract}
Magnetotelluric sounding data have been collected along the Lithoprobe seismic line 21 as a complement to seismic reflection in order to better constrain the structure of the Blake River Group and of the underlying crust. The presence of shallow conductive heterogeneities in an otherwise highly resistive environment typical of the Canadian Shield generates large galvanic distortion that affects the estimates of the impedance tensor. Distortion analysis and tensor decomposition techniques show that MT data support a model represented by a 2D regional model over a 2D deep structure with two different strikes direction and distorted by shallow heterogeneities. The residual static shift affecting each mode for each sounding site is determined using a combination of techniques: shifting the apparent resistivity curves to a reference curve obtained by the authors in the region using $100 \mathrm{~km}$ long dipoles, a shallow resistivity estimate using TDEM sounding, 2D minimum structure inversion with free static shift factors. The resulting model does not satisfy both TE and TM modes. A better fit is found by trial and error using a 2D anisotropic model. The Blake River Group is represented as an highly anisotropic resistive layer with a possible decrease in thickness from northwest to southeast. The middle crust is moderately conductive and isotropic. The lower crust and upper mantle is found to be anisotropic and conductive. The geometry of the Blake River Group obtained from the MT data is in agreement with previous gravity and seismic studies.
\end{abstract}

\section{Introduction}

The Abitibi Subprovince is part of the Superior Province of the Canadian Shield, and is known to be the largest Archean greenstone belt in the world. The Blake River Group (BRG) lies in the southern Abitibi belt. It is delimited to the north by the Porcupine-Destor fault (PDF) and to the south by the Cadillac tectonic zone (CTZ) and the Pontiac Subprovince (see Fig. 1).

The BRG consists of andesite-rhyolite volcanic complex intruded by granitoides and by diorite-gabbro sills and dykes (Hubert et al., 1984; Ludden et al., 1986). The surface geology of the BRG has been intensively studied because of the economic interest of that major mining region, an important producer of copper, zinc, silver and gold in Canada. However, geometry at depth of the main geological structures is unknown with some exceptions close to mining areas where a large amount of exploration boreholes yield limited depth constraints (1,500 m maximum). Two or three-dimensional images are then crucial to improve our understanding of the relation between the BRG and the neighboring regions (Pontiac Subprovince to the south, Kinojevis Group to the north), and contribute to the determination of its origin and evolution.

Several regional geophysical studies have been recently carried out in the BRG. Interpretation of gravity data (Bellefleur, 1992; Deschamps et al., 1993) indicates that thickness of the BRG increases from East $(6-8 \mathrm{~km})$ to West

Copy right (C) The Society of Geomagnetism and Earth, Planetary and Space Sciences (SGEPSS); The Seismological Society of Japan; The Volcanological Society of Japan; The Geodetic Society of Japan; The Japanese Society for Planetary Sciences.
(10-12 km). The main results were however obtained by interpretation of regional and high-resolution (HR) seismic reflection lines recorded within the Lithoprobe program (Jackson et al., 1990; Green et al., 1990; Adam et al., 1992) NS regional seismic reflection lines 12 and 14 located to the west and east of the BRG respectively and HR profiles $12 \mathrm{~A}$ and 14B. Those studies were completed with Audiomagnetotelluric and Magnetotelluric (AMT/MT) surveys on the eastern (Chakridi, 1991; Kellett et al., 1992a, b) and southern (Kurtz et al., 1992, 1993) Lithoprobe transects across the BRG.

Because of the location of the seismic reflection lines, the vertical extension of the geological structures in the central part of the BRG could not be resolved. To complete the 3D image of the BRG, the EW seismic reflection line 21 (Verpaelst et al., 1995; Dumas, 1995) was acquired during 1990. This line connects line 12A (west) to line 14 (east). Furthermore, a HR survey (line 21-1) coincident with the regional line 21 was also carried out in order to test seismic methodology in mining areas (Perron and Calvert, 1998). The present MT survey was performed along the latter profile to complement those studies.

The main objective of the MT survey was to determine the geoelectric cross-section of the BRG. Benefits from this would include resolving both the resistivity and thickness of the Blake River Group allowing comparison of these results with the other geophysical (gravity, seismic, previous MT) and geological models. For example, Gough (1986) and Jones (1987) have previously shown that there could exist some correlation between the seismic reflectivity and the 

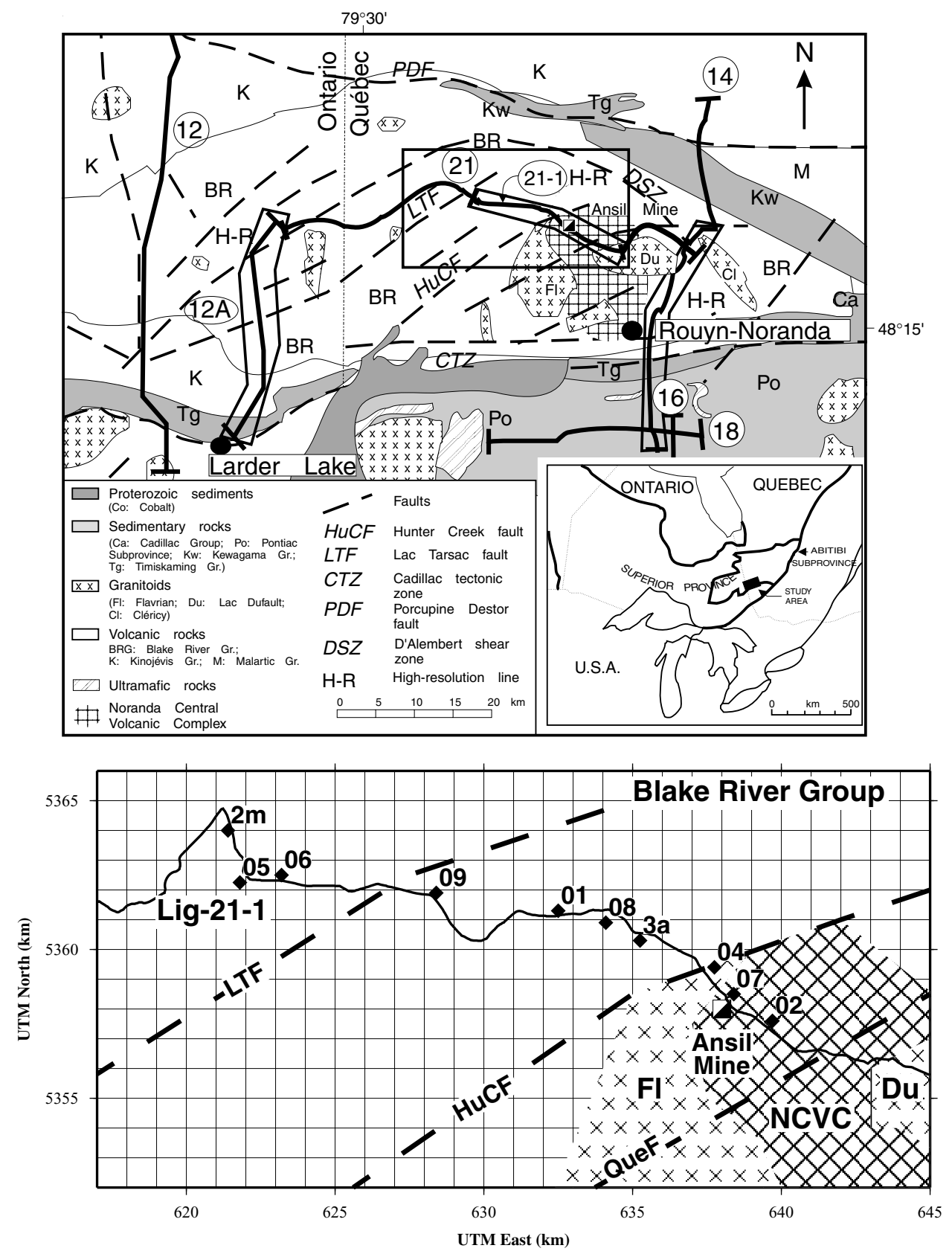

Fig. 1. Top: Location of the Lithoprobe regional seismic lines within the Blake River Group; from Verpaelst et al. (1995). Bottom: Location of the MT sites along the Lithoprobe regional seismic line 21.

MT resistivity data and that both data would help understand the nature of the upper, middle and lower crust, although this is not always true (Cook and Jones, 1995; Clowes et al., 1996).

Another objective of the survey was to test if the Hunter Creek fault (HuCF) (see Fig. 1) had an electrical signature and, if confirmed, what would it tell us on the structure of the BRG. The HuCF is one of several subvertical faults oriented $\mathrm{N} 60^{\circ}$ within the BRG that has been interpreted by Hubert et al. (1984) as normal. As a consequence of its vertical movement, this fault marks the western limit of the Flavrian pluton and the Mine Sequence, a unit of the Noranda Central Volcalnic Complex which hosts most of the ore deposits in the mining camp. One might find north-west of the $\mathrm{HuCF}$ some evidence at depth of the down thrown block of the Flavrian pluton and the Mine Sequence. This information is of great interest for the mining industry as it may provide new targets for exploration of ore deposits at depth.

\section{Data Collection}

Magnetotelluric data were recorded at 9 sites located along the Lithoprobe line 21 (see Fig. 1) using the V5-MT system (Phoenix Geophysics, Toronto). An additional station, site '02m', which is part of the MT soundings analyzed by Zhang et al. (1995), was included in this dataset as it lies on the seismic line.

Two telluric fields $\left(E_{x}, E_{y}\right)$ and three magnetic fields $\left(H_{x}, H_{y}, H_{z}\right)$ at the base station and two reference magnetic 

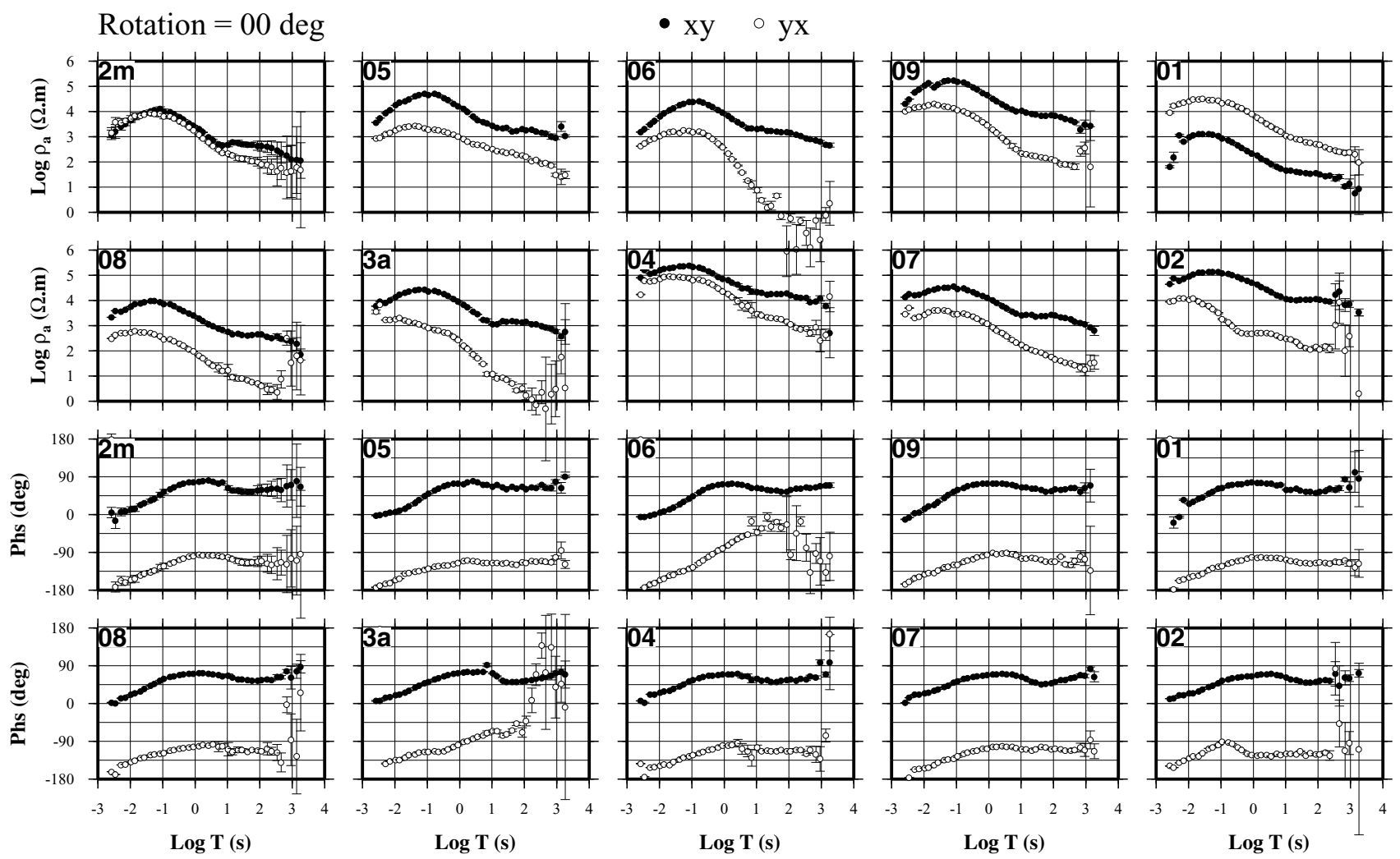

Fig. 2. Measured apparent resistivities and phases sounding curves. Rotation angle is set to N00 so that $\mathrm{X}$ and $\mathrm{Y}$ refer to the north and east direction respectively.

fields $\left(H_{x}^{R}, H_{y}^{R}\right)$ were recorded. Here $(x, y)$ represents respectively geographic north and east directions. From those measurements, impedance tensor elements $Z_{i j}$ were estimated at 40 periods ranging between $2.610^{-3}$ and $1820 \mathrm{~s}$ using real-time processing (cascade decimation) and the remote reference technique (Gamble et al., 1979). Apparent resistivity and phases sounding curves were then computed according to:

$$
\rho_{a}^{i j}=\frac{1}{2 \pi f \mu_{0}}\left|Z_{i j}\right|^{2} \quad \text { and } \quad \phi_{i j}=\arg \left(Z_{i j}\right)
$$

where $f$ is the frequency in $H_{z}, \mu_{0}$ is the permeability of free space and $\{i, j\}$ are the $\mathrm{X}$ and $\mathrm{Y}$ directions.

Data from the two off-diagonal components XY and YX are shown on Fig. 2. Both $\rho_{a}$ and $\phi$ data are of good quality for the whole recorded period band except for the longest periods ( $T>500 \mathrm{~s}$ ). Sounding curves in the XY direction do not vary from site to site while large variations in the YX direction are observed between all the MT sites. In particular, one can observe the particular variations of both $\rho_{a}$ and $\phi$ YX sounding curves for sites $06,3 \mathrm{a}$ and 02 .

\section{Distortion Analysis}

Distortion analysis of the data is used to determine what kind of model may best represent the data, i.e. a regional 1D, 2D or 3D model perturbed or not by local heterogeneities. Such analysis is necessary before performing a realistic interpretation of the observations.

\subsection{Qualitative analysis}

Indexes indicating subsurface geometry defined in Bahr (1991) were computed at each frequency: the phase difference $\mu$, an indicator of one-dimensionality if small values are found; the 2D-rotational invariant $\Sigma$ which indicates if data are supported or not by a 2D conductivity distribution; and the regional skew $\eta$ which is a good indicator of the amount of distortion affecting the data. These three parameters are of particular interest since they do not depend on the regional strike which is one unknown to be determined from the distortion analysis. Accordingly to Bahr (1991), values of $\Sigma>0.1$ indicates a 2D geometry and if $\eta>0.3$ then the regional structure is $3 \mathrm{D}$. Note that those limits are only indicative and could be affected by noise.

Results for each site are presented in Fig. 3. $\mu$ and $\Sigma$ values larger than 0.1 are found for each MT site and for all the frequencies. This clearly indicates that the conductivity structure is at least 2D. However, it can be noticed in Fig. 3 that $\Sigma$ data present for all stations two distinct parts defined from periods smaller or greater than $1 \mathrm{~s}$. This remarkable behavior seems to indicate that the model geometry may be represented by the superposition of a high frequency (shallow) and a low frequency (deep) structure. Values between 0.1 and 0.3 with a mean equal to 0.21 for the regional skew $\eta$ indicate that impedance tensors from the 2D earth are affected by galvanic distortion or that the subsurface is 3D. Therefore a complete distortion analysis of the data is necessary before performing a realistic interpretation of the observations. 

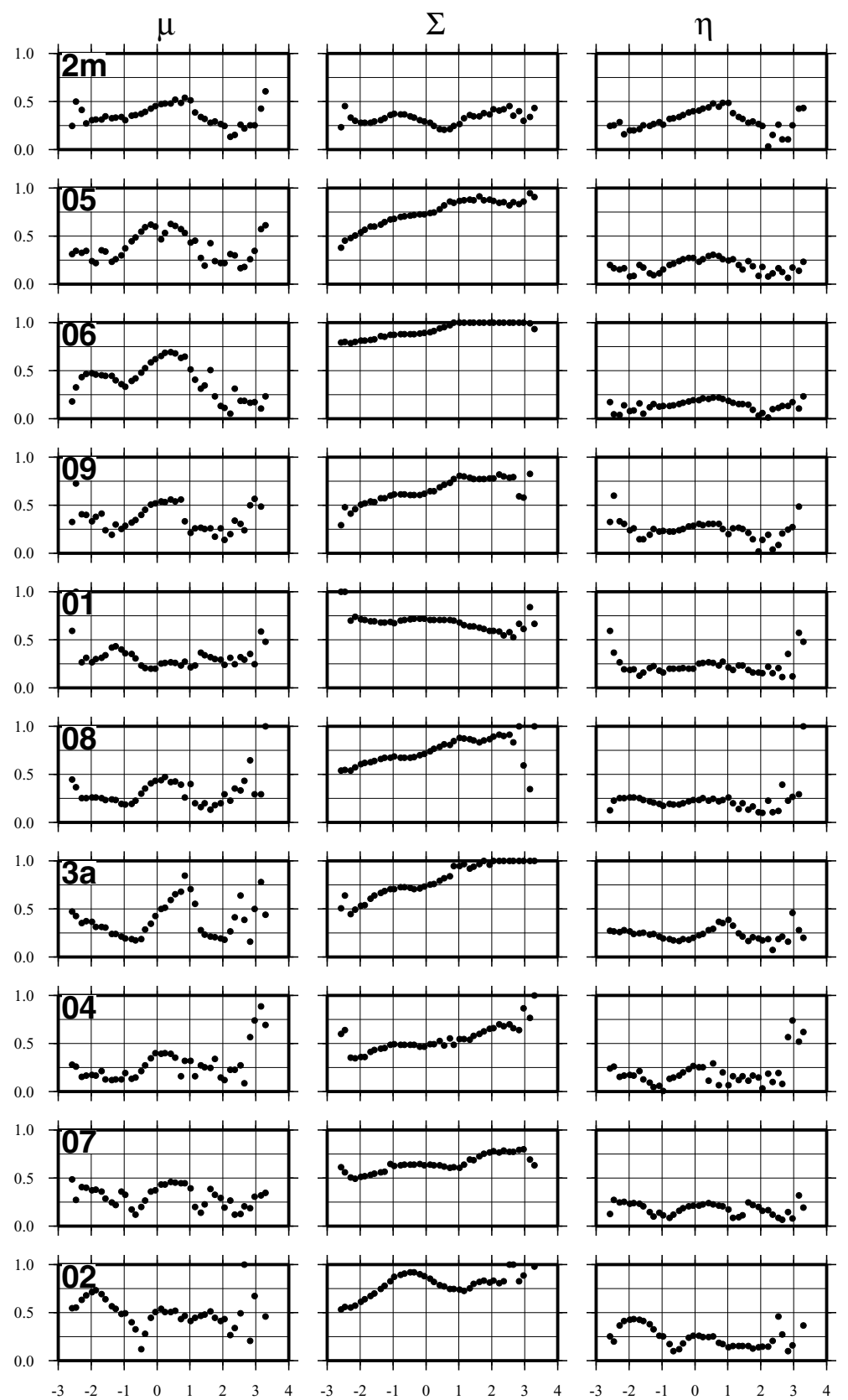

$\log T(s)$

$\log T(s)$

$\log T(s)$

Fig. 3. Bahr parameters $\mu, \Sigma$ and $\eta$. See Bahr (1991) for definition of these parameters.

\subsection{Regional impedances and strike}

To solve for the regional impedances and strike, the disturbed measured impedance tensor $Z_{m}$ can be written as:

$$
\left[Z_{m}\right]=[R(\theta)][D]\left[Z_{r}\right]\left[R^{T}(\theta)\right]
$$

where $[R(\theta)]$ is the rotation operator, $[D]$ the distortion matrix, and $\left[Z_{r}\right]$ the regional impedance tensor. Here, $T$ indicates matrix transpose.

Different strategies for solving this problem have been previously presented (e.g. Bahr, 1988; Groom and Bailey, 1989; Groom et al., 1993). Each of them used different decomposition and parameters (i.e. skew angles $\beta_{1}, \beta_{2}$ in Bahr (1988) or twist and shear in Groom and Bailey (1989)). However, relationships exist between the different types of decomposition (see for example Smith (1995)) indicating that the choice of one specific method is not crucial to the analysis.

One major objective of the MT data analysis is determining the strike orientation for the survey area. Bahr (1991) presents various ways to compute this direction depending on the degree of distortion. However, according to the distortion equation, strike orientation may be viewed as a particular distortion parameter. Furthermore, Groom et al. (1993) and Jones and Groom (1993) have shown that strike estimation is less stable than the determination of the distortion parameters, so that it may be calculated at the same time as the distortion parameters.

We have selected Smith's approach (Smith, 1995) be- 
a)
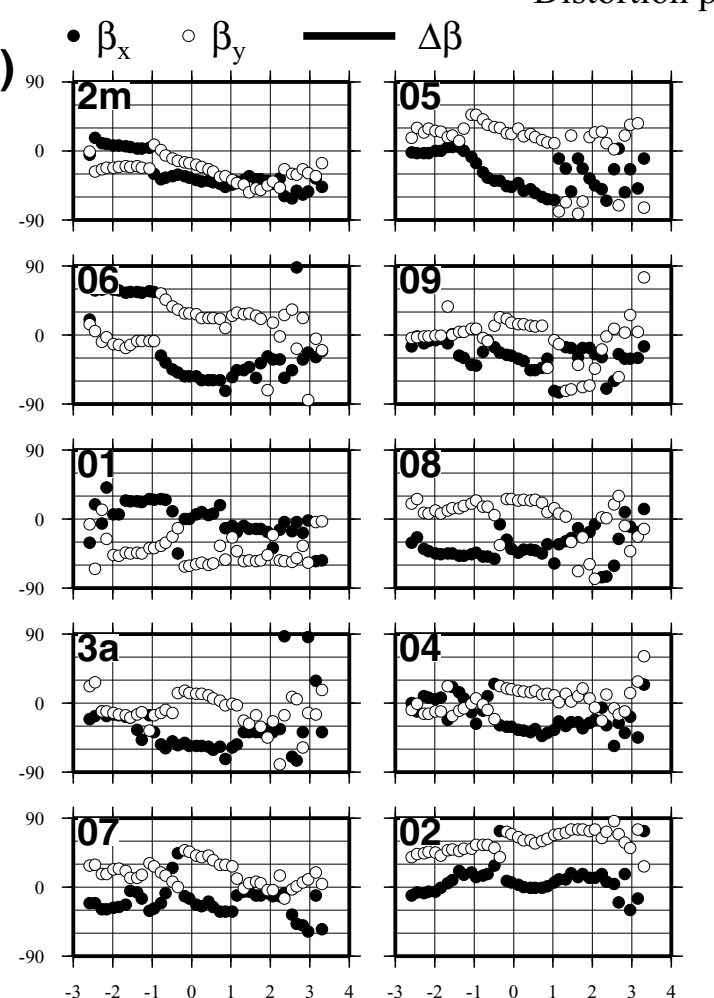

$\mathbf{T}(\mathbf{s})$
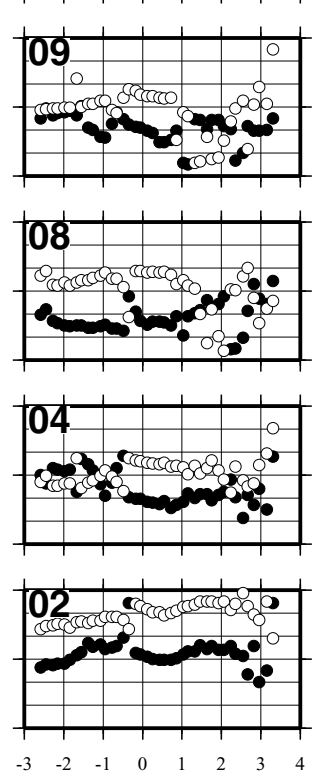

$\mathbf{T}(\mathbf{s})$ b)
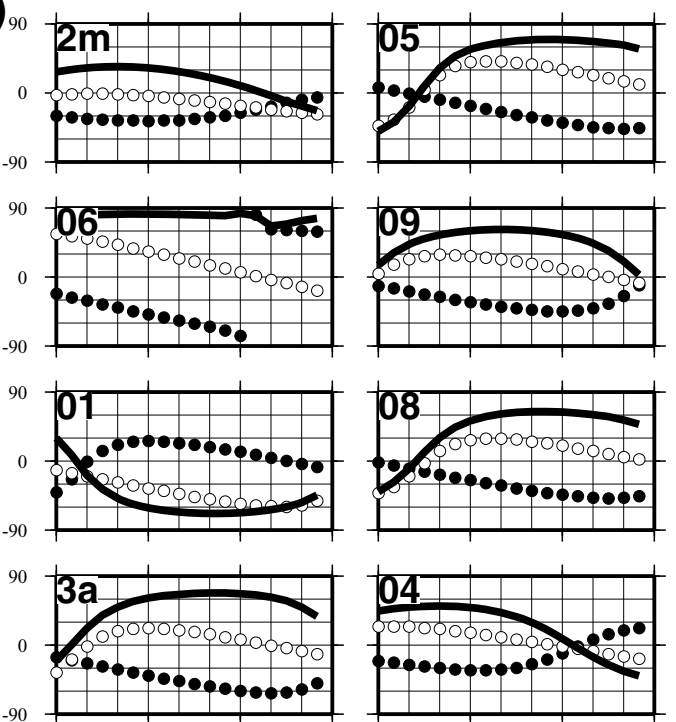

$-90$
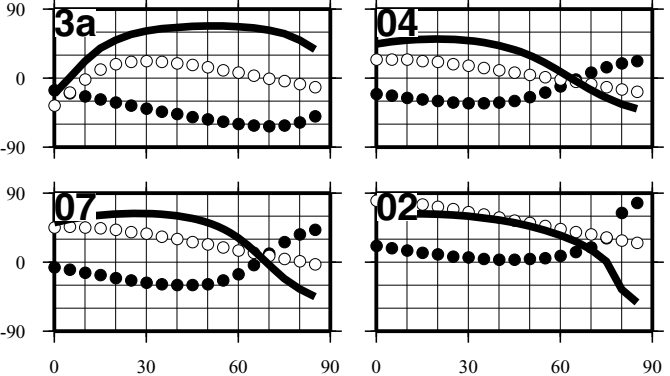

strike

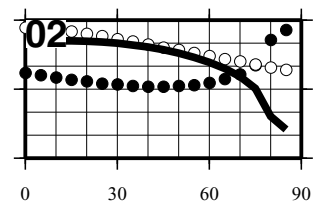

strike

Fig. 4. Frequency-dependent and -independent distortion parameters ( $\beta_{x}$ and $\beta_{y}$ ) computed at each MT-site. (a) (columns 1 and 2) displays the $\beta$ 's as a function of period (frequency-dependent strike). (b) (columns 3 and 4) presents the frequency-independent parameters estimated at each site as a function of strike. Values of $\Delta \beta$ are equal to $-\beta_{x}+\beta_{y}$.

cause his solution is correlated with a simple physical interpretation of the distortion matrix, i.e. according to the rotation angle of the measured $E$ fields, and because a simple procedure is used to calculate simultaneously distortion and strike parameters for individual and groups of MT-sites. Smith's decomposition is comparable with the one of Bahr (Bahr, 1988) where distortion parameters are defined by the $x$ and $y$ electric field rotation (measured clockwise) angles $\beta_{x}$ and $\beta_{y}$ respectively so that:

$$
[D]\left[Z_{r}\right]=\left[\begin{array}{cc}
\cos \beta_{x} & -\sin \beta_{y} \\
\sin \beta_{x} & \cos \beta_{y}
\end{array}\right]\left[\begin{array}{cc}
0 & g_{x} Z_{r}^{12} \\
g_{y} Z_{r}^{21} & 0
\end{array}\right]
$$

where $g_{x}$ and $g_{y}$ represent some gain factors and $Z_{r}^{12}$ and $Z_{r}^{21}$ the two 2D regional impedance elements.

Figure 4 shows variations of both distortion parameters $\beta_{x}$ and $\beta_{y}$ as a function of period (4(a); columns 1 and 2) and of strike angle (4(b); columns 3 and 4) computed for each MT site. Results show that the level of distortion varies from site to site. Figure 4(a) shows period-dependent distortion parameters $\beta_{x}$ and $\beta_{y}$ obtained from fitting Eq. (3) to the measured data; one can observe at several sites (e.g. $2 \mathrm{~m}, 05$, $06,3 \mathrm{a}, 04)$ a break in the curves between 0.1 and $1 \mathrm{~s}$ limiting two nearly linear portions. This behavior is consistent with the one previously displayed by $\Sigma$ (Fig. 3 ). The other sites (e.g. 09, 08, 07, 02) show continuous dependence of the $\beta$ 's versus period $T$. Furthermore, Eq. (3) was solved for $[D]$ for each strike using data at all periods and assuming $[D]$ to be constant (period-independent) for each site. A relative correlation between both $\beta_{x}$ and $\beta_{y}$ estimates is observed on Fig. 4(b) where relatively constant $\Delta \beta$ exist over large strike ranges. For most of the stations, the differences $\Delta \beta$ are lower than $75^{\circ}$ except for site 06 where $\Delta \beta= \pm 90^{\circ}$. It can be also observed that the minimum of $\Delta \beta$ (twice the Groom-Bailey shear) is found to be close to $\mathrm{N} 60^{\circ}$ for most sites (e.g. $2 \mathrm{~m}, 04,07)$. Note here that station 06 has been removed for further analysis because of this high degree of distortion consistent with its out-of-quadrant phases (see Fig. 2).

Analysis of the $\beta$ parameters, along with the geometry indexes from Bahr analysis, show that all MT stations are affected by some distortion varying from intermediate to strong. Futhermore, the MT model that seems to best represent the data may be define by a $2 \mathrm{D}$ regional model over 2D deep model with two different strikes and distorted by shallow heterogeneities.

Distortion analysis for the 9 residual MT sites was performed independently and jointly using the short, the long period ranges (cut off at $1 \mathrm{~s}$ ) and the whole period range. Details of the procedure used to calculate simultaneously distortion and strike parameters for individual and group of MT sites may be found in Smith (1995). Results are summarized in Table 1 and indicate that two directions can be isolated: $\mathrm{N} 60^{\circ}$ and $\mathrm{N} 90^{\circ}$. The first direction of $\mathrm{N} 60^{\circ}$ is observed at short periods $(T<1 \mathrm{~s})$. This direction is the same as the orientation of faults within the Blake River Group (e.g. 
Table 1. Single and multiple site frequency-independent strike and distortion parameters. Label MS indicates the multi-site results and HF, LF and ALL stand for high, low (cut off at $1 \mathrm{~Hz}$ ) and all frequencies respectively. Distortion parameters $\left(\left[\beta_{x}, \beta_{y}\right]\right.$ or [Twist,Shear]) are the ones computed using data from all sites in a multi-site procedure. $\beta_{x}$ and $\beta_{y}$ are the electric field rotation angle as defined by Smith (1995) and Bahr (1988). Twist (tw) and shear (sh) parameters (Groom and Bailey, 1989) are related to $\beta_{x}$ and $\beta_{y}$ by tw $=\left(\beta_{x}+\beta_{y}\right) / 2$ and sh $=\left(\beta_{x}-\beta_{y}\right) / 2$.

\begin{tabular}{ccccccccccc}
\hline Sites & $2 \mathrm{~m}$ & 05 & 09 & 01 & 08 & $3 \mathrm{a}$ & 04 & 07 & 02 & MS \\
\hline$\theta_{\mathrm{HF}}$ & 45 & 65 & 80 & 35 & 75 & 00 & 60 & 50 & 45 & 60 \\
$\theta_{\mathrm{LF}}$ & 50 & 75 & 05 & 85 & 40 & 40 & 05 & 05 & 10 & 90 \\
$\theta_{\mathrm{ALL}}$ & 45 & 65 & 80 & 35 & 75 & 00 & 10 & 10 & 45 & 60 \\
\hline \hline$\beta_{x}$ & -26 & -39 & -45 & 12 & -44 & -60 & -10 & -16 & 8 & \\
$\beta_{y}$ & -17 & 30 & 10 & -56 & 20 & 7 & -2 & 16 & 44 & \\
\hline Twist & -21 & -4 & -17 & -22 & -12 & -26 & -6 & 0 & 26 \\
Shear & -5 & -35 & -28 & 34 & -32 & -34 & -4 & -16 & -18 \\
\hline
\end{tabular}

Torquil Output - Best Strike $=60.0$
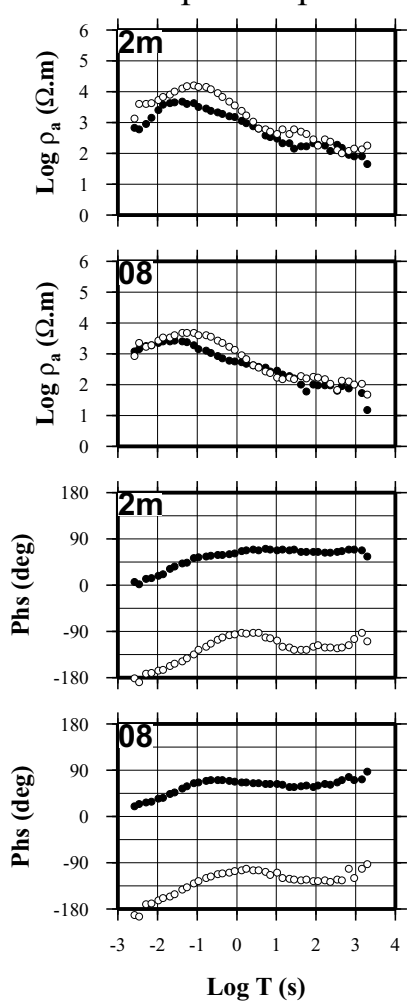
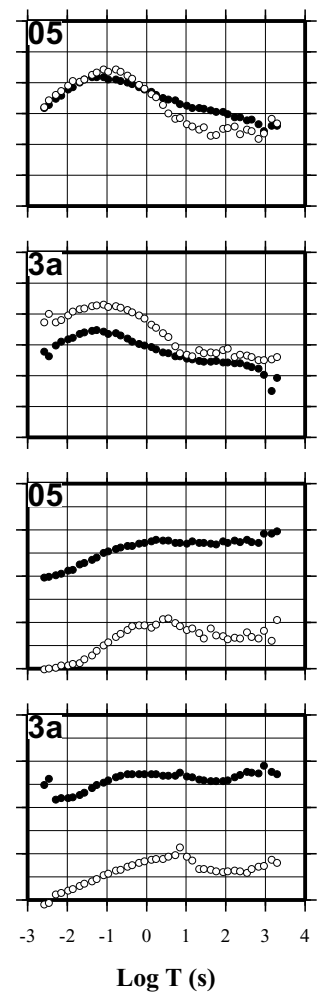

- x'y' $\circ y^{\prime} x^{\prime}$
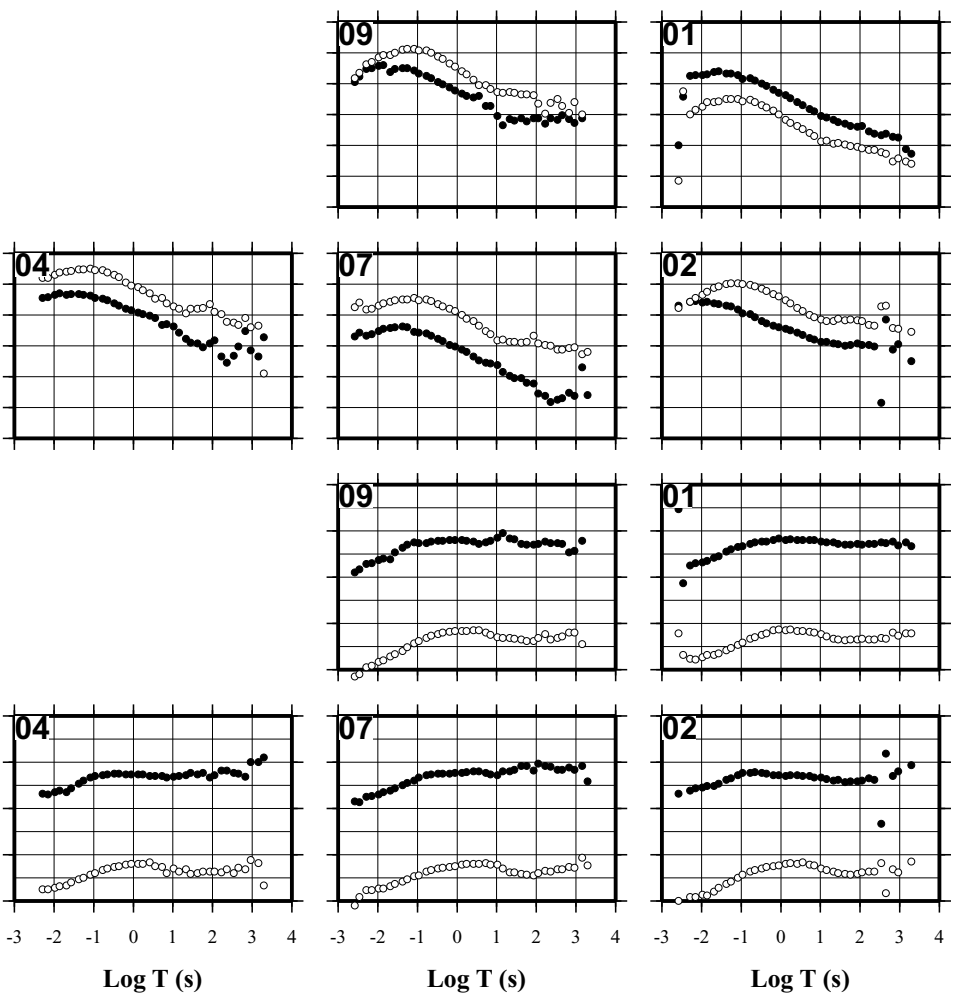

Fig. 5. Apparent resistivity and phase sounding curves corrected for distortion with a strike angle of $60^{\circ}$.

the Hunter Creek (HuCF), Lac Tarsac (LTF) and Quesabe (QueF) faults; see Fig. 1). The second direction $\left(\mathrm{N} 90^{\circ}\right)$ is observed in the long period band $(T>1 \mathrm{~s})$. It corresponds to the general orientation of the major faults bounding the Blake River Group (the Porcupine-Destor fault (PDF) and the Cadillac tectonic zone (CTZ); see Fig. 1).

Finally, the complete set of period-independent strike and distortion parameters were computed in a multiple site analysis using data at all periods (Table 1). The principal strike direction is found to be $\mathrm{N} 60^{\circ}$ which is the direction of faults crossed by the MT survey. Corrected apparent resistivity and phase curves are presented in Fig. 5. Here, it is important to notice that rotation of the impedance tensor in a direction different from the observed strike may result in some distortion of the data and it may affect their interpretation. In this study, rotation from $\mathrm{N} 90^{\circ}$ to $\mathrm{N} 60^{\circ}$ of the long period impedances causes only weak variations in the sounding curves about $T=1 \mathrm{~s}$. Therefore $2 \mathrm{D}$ inversion of the MT data rotated in the $\mathrm{N} 60^{\circ}$ strike direction for the whole period range will yield a resistivity model which is reliable for the upper crust and will provide the general structure for the lower crust and upper mantle.

Phases in each direction are very similar from site to site. This is particularly evident on Fig. 6 which shows the pseudo-sections of $\mathrm{X}^{\prime} \mathrm{Y}^{\prime}$ and $\mathrm{Y}^{\prime} \mathrm{X}^{\prime}$ phases (here, the prime (') denotes $60^{\circ}$ rotated components). Only small lateral variations of both phases can be observed from the west to the east. For $T<1 \mathrm{~s}$, the low phases $\left(\phi<30^{\circ}\right)$ indicate a high 


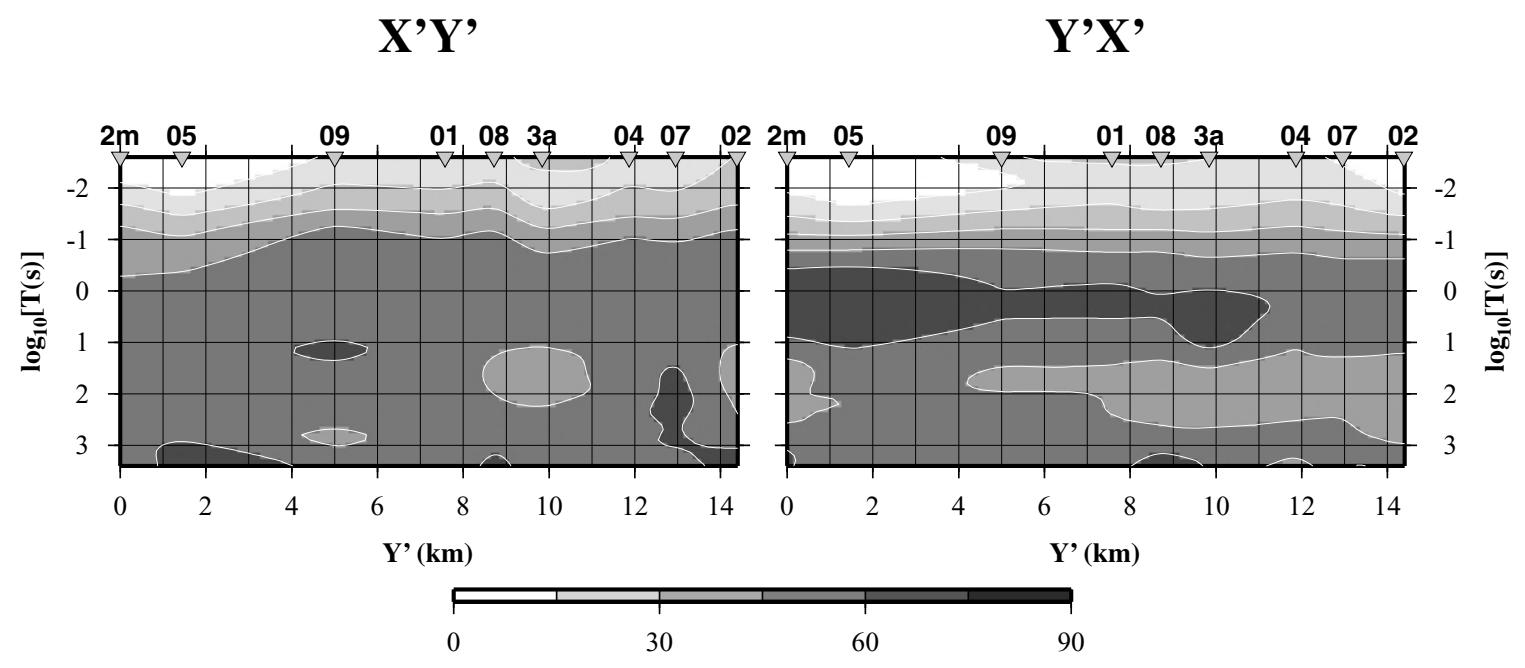

Fig. 6. Phase pseudo-sections of distortion-corrected tensor impedances along a $\mathrm{N} 150^{\circ}$ profile. Note that station 06 has been removed on both figures.

resistivity contrast near the surface: e.g. $\rho_{2} \gg \rho_{1}$ where indexes 1 and 2 stand for the shallow first layer (overburden) and the second layer (resistive bedrock) respectively. For $T>1 \mathrm{~s}$, the $\phi_{x^{\prime} y^{\prime}}$ phases do not vary much and remain greater than $45^{\circ}$. This seems to indicate a relatively constant decrease of resistivity with depth. Variations are more important in the orthogonal ( $\left.\mathrm{Y}^{\prime} \mathrm{X}^{\prime}\right)$ direction. The $\phi_{y^{\prime} x^{\prime}}$ phase increases up to $75^{\circ}$ between 1 and $10 \mathrm{~s}$, and then decreases down to $45^{\circ}$ between 10 and $100 \mathrm{~s}$. This response would indicate that a conductive zone might exist at depth.

The shape of the observed apparent resistivity sounding curves does not change from site to site. However, a vertical separation still exists between the different curves indicating the presence of some static shift in the data. Such shift cannot be resolved by the distortion analysis. Resolution of the static shift is important for the determination of the geoelectric model since unbiased apparent resistivity curves are needed to determine actual depths, geometry and resistivities of the subsurface model. One solution to remove the static shift is to use a-priori or external information about the conductivity structure near the surface or at large depths. Corrections for the static shifts of the $\rho_{a}$ curves for all the MT stations will be discussed in the $2 \mathrm{D}$ inversion section.

\section{Magnetic Induction Vectors}

The observed vertical magnetic field is well correlated with the horizontal magnetic field components only for periods lower than $1 \mathrm{~s}$. Magnetic transfer functions (TF) corrected for galvanic distortion accordingly to Zhang et al. (1993) display a maximum amplitude around $T=0.1 \mathrm{~s}$ (see TF for site 01 , rotation to $\mathrm{N}^{\circ} 0^{\circ}$, on Fig. 7). Real induction vectors for all the MT sites are therefore plotted for $T=0.1 \mathrm{~s}$ using the reversed direction convention (Fig. 7). An eigenvector-eigenvalue analysis was performed on the real induction vectors of all sites. It yielded two eigenvectors, one of direction $\mathrm{N} 74^{\circ}$ and the second, orthogonal, of direction N164 ${ }^{\circ}$. Projection of the in-phase induction vectors into this basis at each site allows the estimation of regional and local contributions to the vertical magnetic field (Fig. 7).
It is clear that the major component $\left(\mathrm{N} 74^{\circ}\right)$ of the induction vectors points toward some conductive zone to the East. It also displays an increasing amplitude from west to east along the profile. The magnitudes of the minor component $\left(\mathrm{N} 164^{\circ}\right)$ are very small $(<0.1)$, and direction changes along the profile may be caused by estimation errors.

Those observations seem to indicate the absence of strong resistivity contrast along the profile and the presence of a conductor or conductive zone to the east of the profile. However, no major conductors can be identified from airborne EM data (MRN, 1986). Furthermore, it had been noticed from a MT study (Chakridi, 1991) located to the east of station 02 along NS seismic line 14 that a strong correlation exists between the in-phase induction vectors and the direction of domestic power lines in the region. Chakridi noted that all in-phase induction vectors point at the power lines and magnitude peaks at $T=0.1 \mathrm{~s}$. Geomagnetically Induced Currents (GIC) are generated in power lines accordingly to Ohm's law because of voltage drop (caused by the MT E-field) between two grounding sites. Low frequency currents flow in the neutral cable with the currents returning through the ground. This horizontal current filament causes a magnetic field with a large vertical component that can be mistakenly recorded as generated by subsurface heterogeneities. GIC's increase with the ground resistivity, the incident geomagnetic field strength and high frequency content. In fact, it can be shown that the magnetic transfer function caused by the power lines is proportional to the ground impedance (see appendix). Here, in this study, the largest impedances occur at about $10^{-1} \mathrm{~s}$ as evidenced by the high apparent resistivities in Fig. 2. Those observations suggest that observed magnetic transfer functions might be caused by a NW-SE Hydro-Quebec electric power line located to the east of station 02 .

\section{1D Inversion}

A general first order 1D model for all the MT sites is obtained from an average 1D impedance estimated for the survey area as the arithmetic mean of all effective determinant impedances $Z_{\text {det }}$ (see Hobbs, 1992, for definition) computed 
a)
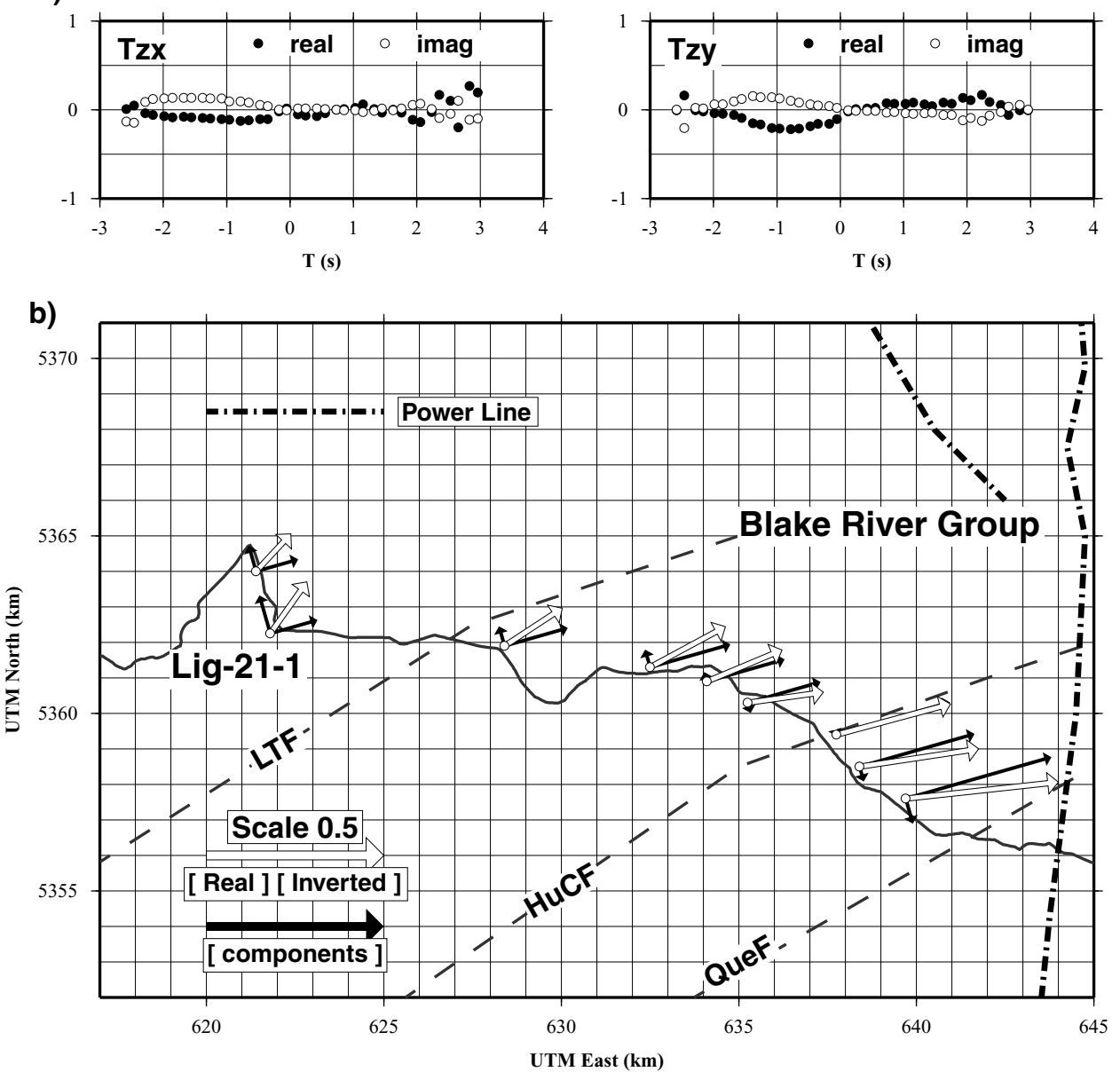

Fig. 7. (a): Vertical magnetic field transfer functions $T_{z x}$ and $T_{z y}$ for site 01 plotted according to period (rotation set to N00 ${ }^{\circ}$ ). (b): Regional part of the reversed real induction vectors at $T=0.1 \mathrm{~s}$ computed from the decomposition presented in Zhang et al. (1993). The regional induction vectors (white arrow) are further projected into the orthogonal directions $\mathrm{N} 74^{\circ}$ and $\mathrm{N} 164^{\circ}$ (black arrows).
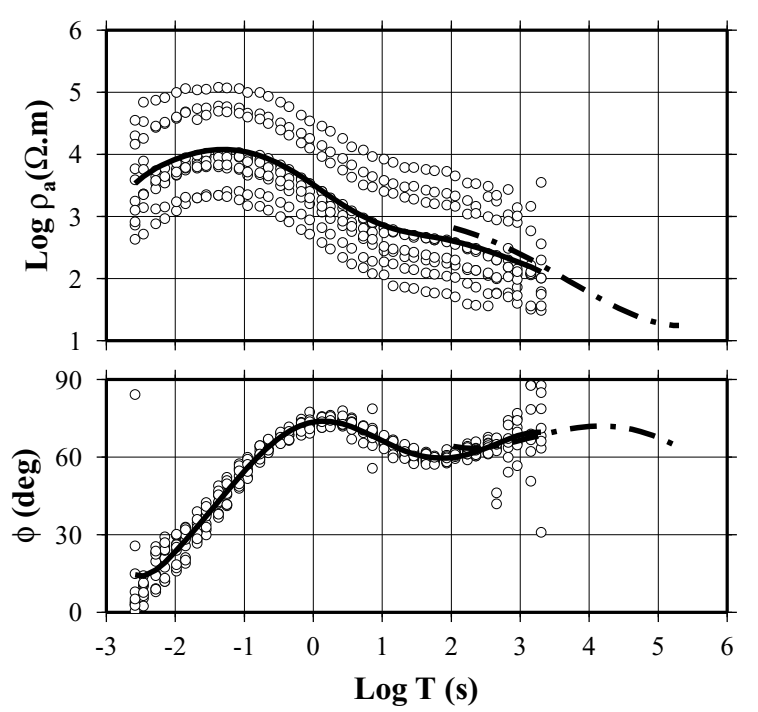

Fig. 8. Apparent resistivities and phases of the determinant impedances for all the MT stations (circles). Apparent resistivity and phase sounding curves for the computed arithmetic mean $\left(\overline{Z_{\mathrm{det}}}\right)$ of all effective determinant $Z_{\text {det }}$ are drawn with a thick line. The regional reference curves from Tournerie and Chouteau (1998) are also shown (dash-dot) for the range $\left[10^{2}-10^{5}\right] \mathrm{s}$.
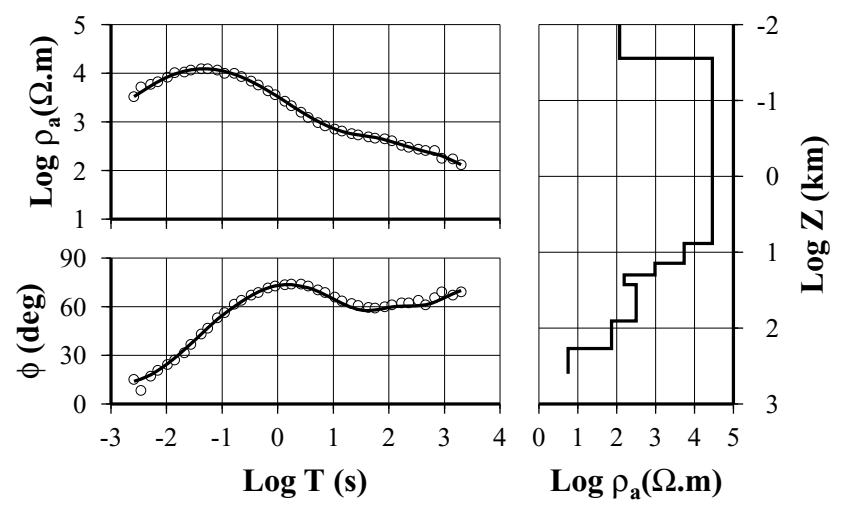

Fig. 9. Results of the 1D layered-earth inversion of apparent resistivity and phase sounding curves computed from $\overline{Z_{\text {det }}}$.

at each MT site. On Fig. 8, it can be noted that the average determinant $\rho_{a}$ and $\phi$ sounding curves shows good continuity on the overlapping period range $\left(10^{2}-2.10^{3} \mathrm{~s}\right)$ with the $Z_{\text {det }}$ curves computed from the regional MT-impedances of Tournerie and Chouteau (1998). The 1D layered-earth inversion (Fig. 9) indicates that the resulting model is similar to the one estimated by Tournerie and Chouteau (1998) and 
may then represent a good starting model for 2D inversions.

Interpretation of three regional seismic lines recorded in the BRG, lines 12 and 14 (Jackson et al., 1990; Green et al., 1990) and line 21 (Verpaelst et al., 1995; Dumas, 1995) (see Fig. 1), are all consistent with a similar first order vertical structure from the surface down to the upper mantle defined by the seismic reflectivity: (1) a weakly reflective upper crust (0-4 s); (2) a strongly and heterogeneously reflective middle crust (4-9 s); (3) a downward decreasing reflectivity lower crust (9-13 s); (4) an unreflective upper mantle $(>13 \mathrm{~s})$. The base of the BRG is recognized to be at the upper/middle crust interface $(4 \mathrm{~s}$ or $\simeq 12 \mathrm{~km})$ and the Moho's limit between 11.5 and $12 \mathrm{~s}(\simeq 40 \mathrm{~km})$.

Its follows that a correlation exists between the general seismic reflectivity image and the geoelectric $Z_{\text {det }}$ model. In particular, the limit between the volcanics (upper crust) and the metasedimentary rocks (middle crust) is associated with the seismic reflectivity (Green et al., 1990; Jackson and Cruden, 1995). Variation of the resistivity at depth seems to be correlated with that limit. In fact, this study of $Z_{\text {det }}$ data show that BRG upper crust (volcanics) has a resistivity of about $10^{5} \Omega$.m. Gneisses of the Pontiac Subprovince are thought to exist under the BRG (see figure 6 in Chown et al., 1992). Analysis of MT data from the Pontiac Subprovince (Kellett et al., 1992b) indicated a resistivity of about 5000 $\Omega . \mathrm{m}$ for the metasedimentary rocks. Pressure and temperature conditions in the middle crust may decrease resistivity further. Correlation between transparent and resistive zone has been previously mentioned in Gough (1986) and Jones (1987) and illustrated in many cases (e.g. Kellett et al., 1994; Marquis et al., 1995; Bitri et al., 1997). Variation in depth estimates between the seismic image and the MT model may be due to some error in the estimation of the MT-static shift parameters, in the approximate correlation between reflectivity and resistivity contrast or in the lower resolution of the MT method compared with the seismic reflection method.

\section{2D Inversion}

Based on the distortion analysis, the subsurface appears mainly 2D; therefore $2 \mathrm{D}$ inversion was attempted. The position of all MT sites were projected onto a profile oriented $\mathrm{N} 150^{\circ}$ before $2 \mathrm{D}$ inversion. This direction was selected because the "best" regional strike is of direction N60 corresponding to the TE mode for $2 \mathrm{D}$ structures. This orientation also happens to be not far from the general $\mathrm{N} 110^{\circ}$ orientation of the Lithoprobe seismic line 21 (see Fig. 1). The transverse electric (TE) and transverse magnetic (TM) impedances are then defined as the $X^{\prime} Y^{\prime}$ and $\mathrm{Y}^{\prime} \mathrm{X}^{\prime}$ impedances with directions $\mathrm{N} 60^{\circ}$ and $\mathrm{N} 150^{\circ}$ respectively.

Data have been inverted using the RRI algorithm of Smith and Booker (1991). Several common parameters were used in both TE and TM inversions. We have selected the $Z_{\text {det }}$ $1 \mathrm{D}$ model as starting model. Error floor for the apparent resistivities and the phases were set to $10 \%$ and $5 \%$ respectively. Furthermore, the relative importance of the horizontal versus vertical second derivative of model parameters in the RRI misfit function (see Smith and Booker (1991) for definition) was reduced by setting the weighting parameter $\alpha$ to unity.
In the previous section, it has been demonstrated that the $\rho_{a}$ sounding curves are all affected by statics shifts (see Fig. 5). Removal of statics shifts has been studied extensively (e.g. Jones, 1988; Singer, 1992); however no method has yet been found that unambiguously correct data from this effect. Static shift may be estimated by using some apriori or external information about the conductivity structure near the surface or at depth. Tournerie and Chouteau (1998) obtained for this region of Abitibi long period $\rho_{a}$ and $\phi$ sounding curves free from galvanic distortion and from static shift because telluric data were collected using electric dipoles of about $100 \mathrm{~km}$. This dataset represents a long period reference for the BRG. Consequently, TE and TM $\rho_{a}$ sounding curves for site $2 \mathrm{~m}$ were shifted to that regional resistivity reference. Futhermore, site correction has also been performed to agree with the results from time-domain EM measurements done near site $2 \mathrm{~m}$ indicating a first layer with a conductance of about 0.5 Siemen and a resistivity ratio $\rho_{2} / \rho_{1}>100$. This model was used to calculate an apparent resistivity at $10 \mathrm{kHz}$. Extrapolation of the $\rho_{a}$ sounding curves for site $2 \mathrm{~m}$ for frequencies greater than $300 \mathrm{~Hz}$ shows that curves converge towards this high frequency limit. Finally, TE and TM $\rho_{a}$ curve of the others MT sites were adjusted to those of station $2 \mathrm{~m}$ so that they lay on top of one another. The results are presented in Fig. 10(a).

A second solution is to consider the resolution of the static shifts within the 2D inversion algorithm. Static parameters are then considered as particular unknowns of the model, and they are calculated such that the inverted model displays minimum structure. The 2D MT inversion program RRI developed by Smith and Booker (1991) includes static shift estimation at each observed site, and it was used herein for that reason. Different combinations of both starting model and starting static shift coefficients have been experimented. Only site $2 \mathrm{~m}$ was not allowed to be shifted, its level being determined by the TDEM data. Statics shifts computed in that way are generally lower than those estimated using apriori information but variations between both methods are relatively small.

The final models computed from inversions of both TE and TM data corrected for statics (Fig. 10(a)) are shown in Fig. 11. The relatively large ratio between the TM and TE apparent resistivities $\left(\rho_{a}^{\mathrm{TM}} / \rho_{a}^{\mathrm{TE}} \simeq 10\right)$ results in large differences in the thickness of the upper crust layer between the two models. In the TE model, upper crust is found to be approximately $5 \mathrm{~km}$ thick with a resistivity of $10^{4} \Omega . \mathrm{m}$ while a thickness of $30 \mathrm{~km}$ and a resistivity of $10^{5} \Omega . \mathrm{m}$ are obtained in the TM model. Joint inversions of TE and TM data were performed with same statics shifts parameters. Results, not presented here, showed a bad adjustement between computed and observed data. In particular, none of the trials was able to fit shape and amplitude variations in $\rho_{a}, \phi$ TE and TM curves. This result is consistent with separate inversions of TE and TM mode that display a large difference in the resulting models.

In order to correct models from thickness variations between TE and TM mode, apparent resistivities sounding curves presented in Fig. 10(a) were all shifted upward for TE and downward for TM by half a decade. Final $\rho_{a}$ sounding curves are then at the same amplitude level than the one of 

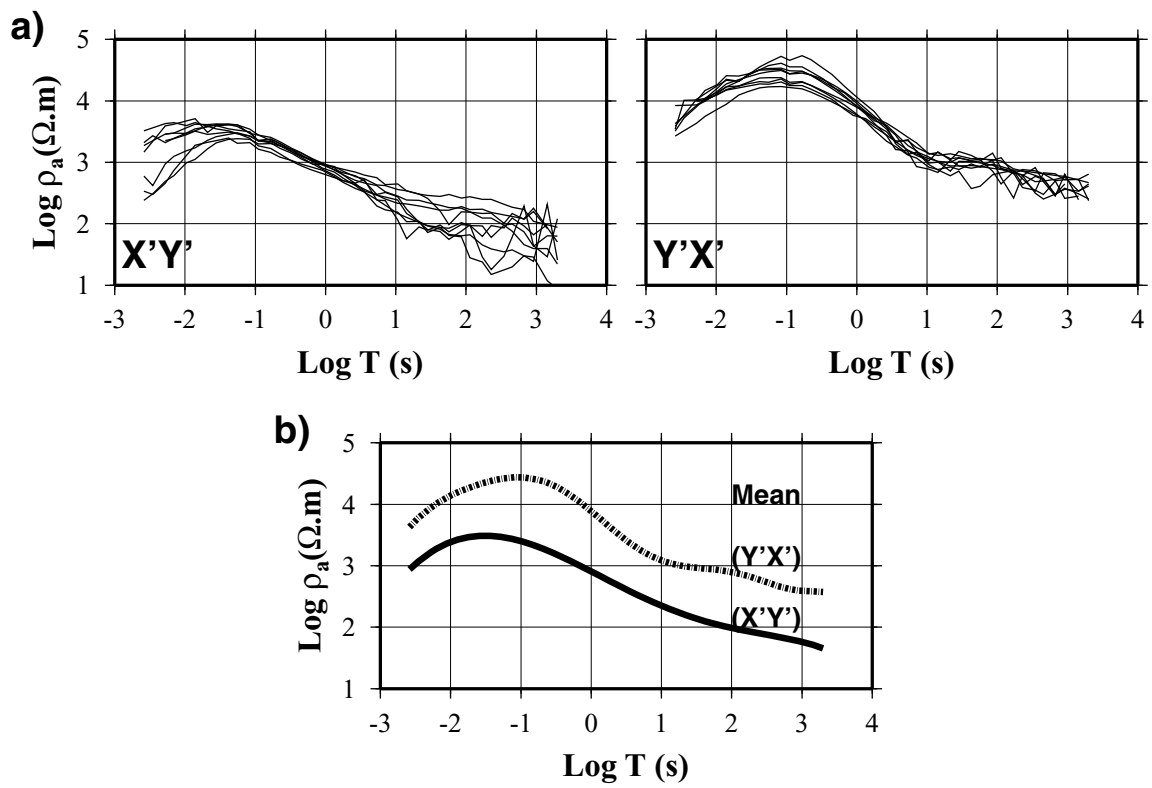

Fig. 10. (a): Apparent resistivity sounding curves for both $\mathrm{X}^{\prime} \mathrm{Y}^{\prime}$ (TE) and $\mathrm{Y}^{\prime} \mathrm{X}^{\prime}$ (TM) modes corrected for static shift using TDEM sounding at site $2 \mathrm{~m}$ and regional impedances obtained by Tournerie and Chouteau (1998). (b): Computed geometric mean of TE and TM $\rho_{a}$ sounding curves.

TE

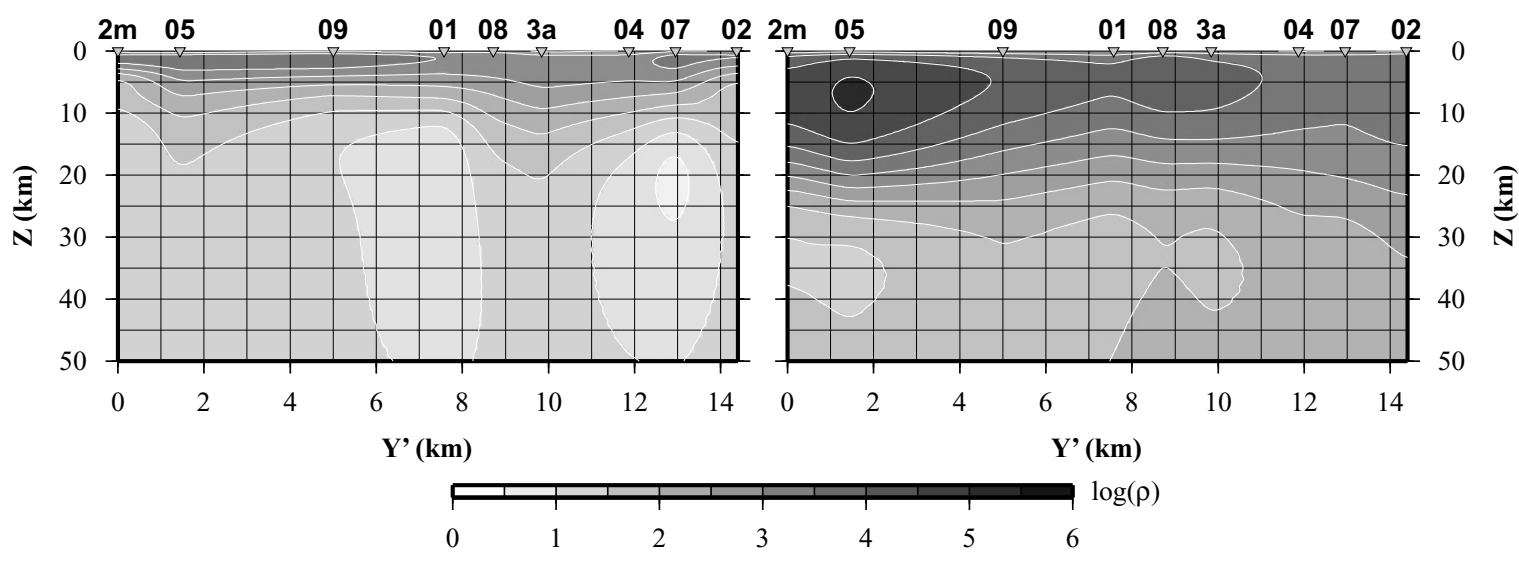

Fig. 11. 2D RRI inversion: TE and TM models computed from the apparent resistivities (corrected for static shift according to Fig. 10) and phases.

the $Z_{\text {det }}$ model (Fig. 8). Results of the TE and TM inversions of this second dataset are presented in Fig. 12. Models have a similar structure to the ones displayed in Fig. 11 and are characterized by an high resistive upper crust $\left(\simeq 10^{5} \Omega . \mathrm{m}\right)$ from surface down to $10-15 \mathrm{~km}$. Resistivity and thickness of this layer seems to vary along the profile from $10^{5} \Omega . \mathrm{m}$ and $10 \mathrm{~km}$ at site $2 \mathrm{~m}$ to the $10^{4} \Omega . \mathrm{m}$ and $6 \mathrm{~km}$ at station 02 . From 15 to $30 \mathrm{~km}$, we can clearly observe in the TM model a conductive zone of about $100 \Omega . m$ before the decrease of the resistivity at depth $(5 \Omega . \mathrm{m}$ at $200 \mathrm{~km})$. This moderately conductive zone seems to be not as well displayed in the TE model.

Depths that define the upper, middle and lower crust using the second set of static shift parameters are similar in both TE and TM models and are approximatively the ones determined in Tournerie and Chouteau (1998). Allthough some improvement in the fit between the TE and TM data is observed compared to the previous selection of static shift coefficients, the resulting model is found not satisfactory; measured sounding curves in both directions are not well fitted by the computed response from the final output model of the joint inversion. This indicates that a $2 \mathrm{D}$ isotropic model may not well completely explain the data.

In order to accommodate both TE and TM mode data, a 2D regional anisotropic model may be considered. This has been previously proposed by Kellett et al. (1992b) for the Pontiac Subprovince, by Mareschal et al. (1995) for the Kapuskasing Structural Zone, and by Eisel and Bahr (1993) and Jones et al. (1993) for the BC87 (British Columbia) data. In these models, geoelectrical structures may have dif- 


\section{TE}

TM
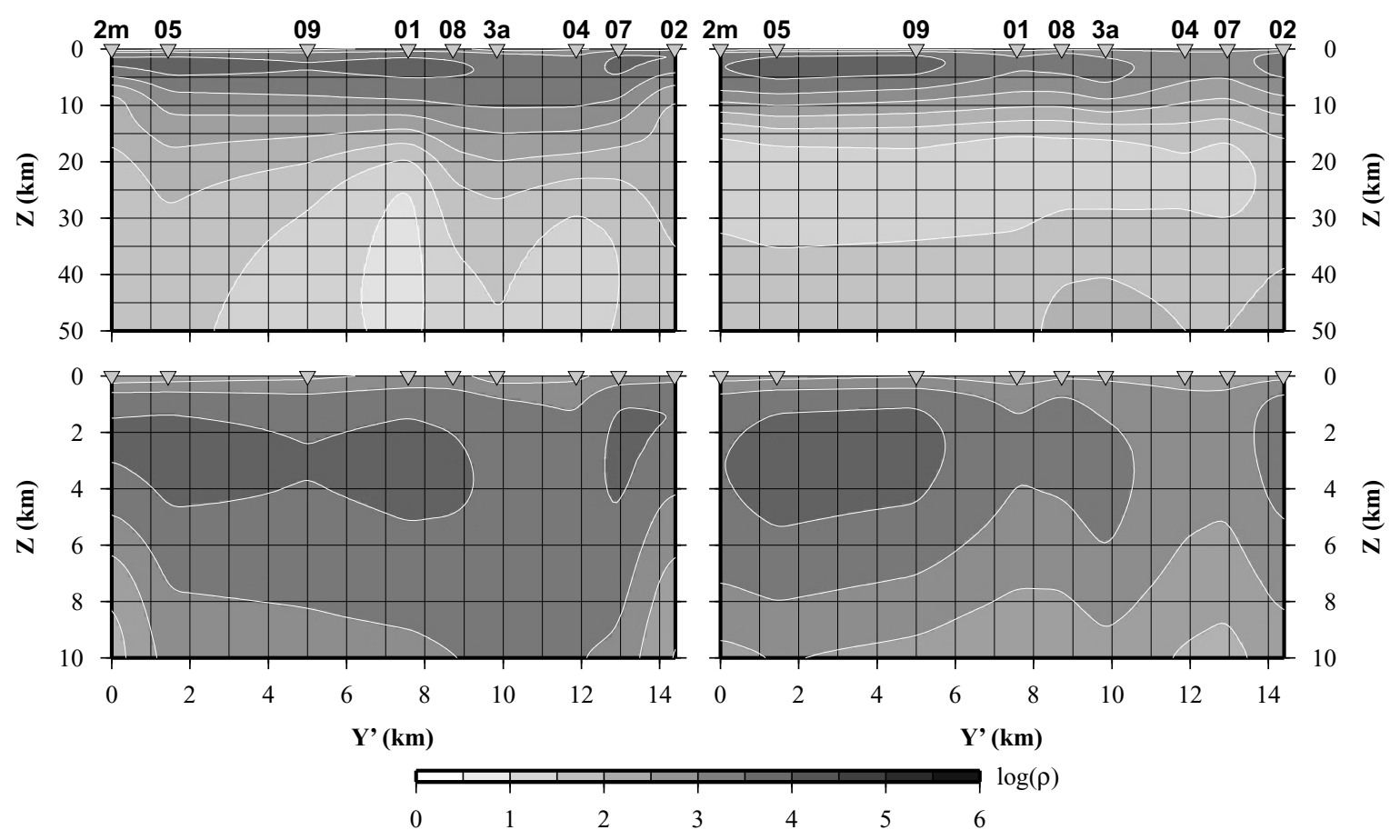

Fig. 12. Final TE and TM models computed from the second set of static shift coefficients.

ferent resistivities in the two horizontal directions for some depth range. Results of our inversion trials are in favour of this model as it can be observed in Figs. 11 and 12 that different resistivities are obtained in the two orthogonal directions at same depth. They are also evidences for an anisotropic resistivity model. First, the vertical field generated by the TE mode (horizontal magnetic field in the $\mathrm{N} 150^{\circ}$ direction) is almost nil. Second, the shape of the resistivity curves at all site for each mode are very similar within a static shift factor (Fig. 10). However, both TE and $\mathrm{TM}$ remain different indicating either a $2 \mathrm{D}$ subsurface or an anisotropic quasi-layered earth. The similarity of the sounding curves at each site for the whole profile $(15 \mathrm{~km})$ and the absence of vertical magnetic field tell in favour of an anisotropic earth.

2D anisotropic MT inversion programs are not commonly available. Therefore we have developed a suitable model using a 2D forward modelling code developed by Pek and Verner (1997). An initial model was developed from onedimensional anisotropic inversion of TE/TM data at each site corrected with the set of static shifts parameters estimated in the first RRI model obtained (Fig. 10). The model was then simplified to yield the one presented on the top of Fig. 13. Deeper part of the model was also controled by the $Z_{\text {det }}$ model and the 1D anisotropic model of Tournerie and Chouteau (1998). The anisotropy contrast for the upper crust was set to $10^{4}-10^{6} \Omega . \mathrm{m}$ (TE/TM) in order to adjust the measured apparent resistivities at high frequencies.

Results are presented here as pseudo-sections of the computed TE and TM phases (bottom of Fig. 13) that can be compared with the measured phases (Fig. 6); the response of the 2D anisotropic model adjusts the major features of both the TE and TM data curves. In particular, the phase anomaly found in the data between $10^{0}-10^{1} \mathrm{~s}$ is well reproduced. Futhermore, magnetic tranfer function computed using this 2D anisotropic model remain very small for the whole period range and all along the profile. These results demonstrate that the 2D anisotropic model may be considered as a potential candidate to represent the observed MT data collected in the BRG. In fact, this 2D anisotropic model contrary to the models obtained by the RRI inversion, is the only one that simultaneously fits both TE and TM modes. The principal structures of the BRG which are displayed in the anisotropic model are: (1) a weakly conducting overburden overlying a resistant upper crust; (2) a decrease of thickness of that crust from the north-west to the south-east; (3) an electrical anisotropy of the upper crust and of the upper mantle.

\section{Discussion}

The western part of our survey can be directly connected to the AMT model presented in Zhang et al. (1995) as both studies used station $02 \mathrm{~m}$. Both interpretations have found a relatively conductive overburden with a conductance of about 0.5 Siemen and a hight resistive upper crust of at least $\simeq 10^{4} \Omega . \mathrm{m}$ and $10 \mathrm{~km}$ thick. Our model is also consistent with results from several MT studies performed in the area of the BRG: NS profile east of the BRG (Kellett et al., 1992a, b); EW line to the south (Kurtz et al., 1992, 1993). In each cases, a resistive upper crust with a resistivity greater than $10^{4} \Omega . m$ has been interpreted.

Lateral variations in the geoelectric model are very small 


\section{D Anis. Model}
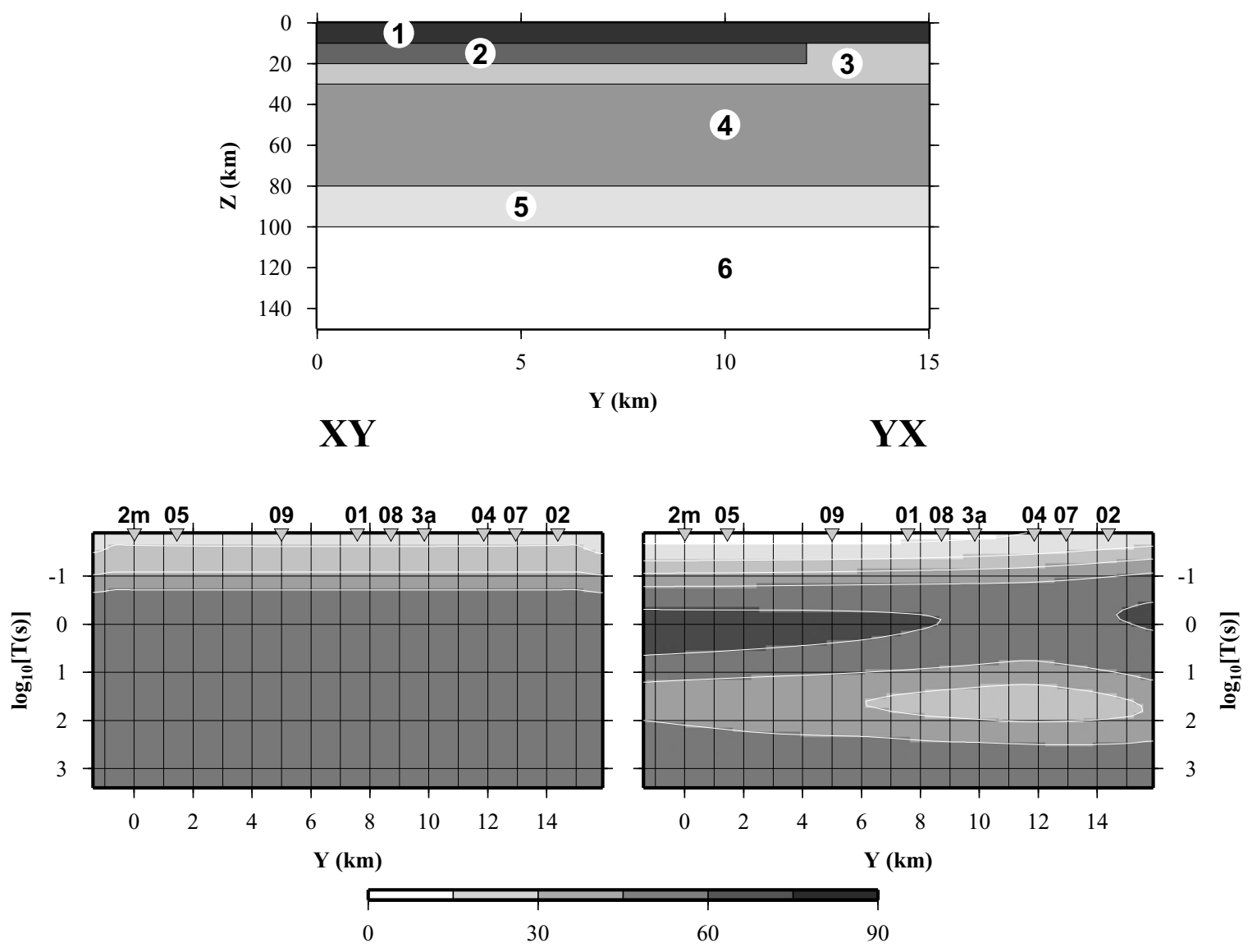

Fig. 13. Top: Two-dimensional anisotropic model. Numbers relate to the geoelectrical structures with XY and YX resistivities set as: $[1] \rho_{1}=10^{4} / 10^{6}$ $\Omega . \mathrm{m}$; [2] $\rho_{2}=10^{3} / 10^{5} \Omega . \mathrm{m}$; [3] $\rho_{3}=10^{2} \Omega . \mathrm{m}$; [4] $\rho_{4}=10^{2} / 10^{3} \Omega . \mathrm{m}$; [5] $\rho_{5}=10^{1} \Omega . \mathrm{m}$; [6] $\rho_{6}=10^{0} \Omega . \mathrm{m}$. Overburden (not shown) is 50 m thick with $\rho_{0}=100 \Omega$.m. Bottom: Pseudo-section of the computed XY/YX phases, compare with observed pseudo-section in Fig. 6 .

for depths greater than $30 \mathrm{~km}$. However, analysis of the data, RRI inversion and 2D anisotropic modelling seems to indicate that thickness and resistivity of the upper crust of the BRG decrease from the northwest to the southeast. This lateral variation in depth for the BRG has been previously infered from gravity studies (Bellefleur, 1992; Deschamps et al., 1993) and well imaged by reflection seismic images (Verpaelst et al., 1995; Dumas, 1995). The lateral variation in depth and resistivity is demonstrated by the difference in slope at high-frequency of the apparent resistivity sounding curves from west to east. It is also consistent with the images of the phase pseudo-sections presented on Fig. 6. In particular, the high-resistive and thick upper crust can be clearly delineated in the western part of the profile. The limit of this zone is found to be between MT sites $3 \mathrm{a}$ and 04 , which is coincident with the HuCF zone.

The lateral resolution of the MT image is limited by the high resistivities found for the upper crust as MT response for a $10^{5} \Omega . m$ upper crust looks relatively similar to the one with $10^{4} \Omega$.m. For example, modelling of the $\mathrm{HuCF}$ as a normal vertical fault from surface down to $10 \mathrm{~km}$ reveals that significant variations in the data may be found only with a contrast of $10^{6} / 10^{4} \Omega . \mathrm{m}$ at the fault interface. Further- more, modelling shows that response of the fault model is not different from a model with a continuous variation of the upper crust thickness. This may explain why no vertical structures and no significant EM signature delineating the fault can be clearly identified in our model. The fault itself is not highly conductive as demonstrated by the analysis of the induction vectors of direction $\mathrm{N} 164^{\circ}$ (Fig. 7) and by the lack of airborne EM anomalies over its strike (MRN, 1986). Delineation of specific structures such as the Flavrian Pluton or the Mine Sequence across the HuCF is then difficult. Perron and Calvert (1998) who have analyzed the high-resolution seismic line 21-1 were not able to clearly delineate trace of the Flavrian Pluton west of the HuCF at depth. This is consistent with the detailed geological study of Camiré and Watkinson (1990) who have found no evidence of major lateral displacement and fluid circulation along the HuCF.

Tectonic development of the BRG has been mainly controlled by the movement along the PDF to the north and by the CTZ to the south. The NS compression $(3.4-2.8 \mathrm{Ga})$ followed by the EW dextral transcurrent shearing $(2.8-2.5 \mathrm{Ga})$ (Hubert et al., 1984) have developed the SE-NW faults (e.g. the HuCF, LTF and QueF faults). Different mechanisms may be proposed to explain the observed upper crust 
anisotropy. One may suppose that development of the N60 normal fault system and the vertical movement along it may have juxtaposed different blocks, and therefore generated a lateral variation of the resistivity; e.g. contrast between highly resistive and middly resistive blocks. The observed variation of metamorphism across the HuCF (Camiré and Watkinson, 1990) from prehnite-pumpellyite facies northwest to greenschist facies southest of the fault may support this model. One may also suppose some preferential grain re-alignment along this $\mathrm{N} 60^{\circ}$ direction due to the tectonic events. In both cases, flow of the electric current will be then favored in one specific direction, and give rise to some anisotropy.

Another source of anisotropy may nevertheless be the $\mathrm{N} 60^{\circ}$ faults. Even though not highly conductive the faults could be less resistive that the host rocks because of increased porosity or the presence of alteration material. This would yet be sufficient to provide preferential current flow along their strike. Some bounds can be set on the resistivity of some of the faults in Archean terranes, more specially in the Abitibi Subprovince of the Canadian Shield. Whatever fault is concerned, HuCF, LTF or QueF, there are no airborne EM anomalies associated with them. For the system flown in the mid 80's (Input MK VI), this put a higher bound on the conductivity-thickness product for a vertical sheet conductor to 0.1 Siemen if detected on channel 1 only and 1 Siemen if a coherent response is detected on the three first channels. For a $20 \mathrm{~m}$ wide zone as the $\mathrm{HuCF}$, that means an average resistivity of $200 \Omega . \mathrm{m}$, a upper limit for detection only, and $20 \Omega$.m for picking the anomalous response with certainity. Therefore, as no Input anomaly on channel 1 is detected in the survey area, this sets a lower limit for the fault to about 200 S.m. However MT soundings show a pervasive resistivity anisotropy over the survey profile for the high frequency range with a well-defined direction of $60^{\circ}$ for the minor axis. The resistivity parallel to the faults is about $10^{3} \Omega . \mathrm{m}$ however no appreciable vertical magnetic field is observed. For a vertical fault in an otherwise highly resistive host rock $\left(10^{5}\right.$ $\Omega . \mathrm{m})$ that puts a higher bound on resistivity to about $10^{3}$ $\Omega . m$. Therefore resistivity of the above mentioned faults should be in the range [200-1000 $\Omega . \mathrm{m}]$. This range estimate agrees with Zhang et al. (1995) who model the major faults (Porcupine-Destor and Casa Berardi) in Northern and Central Abitibi as vertical dykes with a resistivity of $1000 \Omega . m$.

Upper mantle resistivity anisotropy characterized in this study has a magnitude of $\rho_{\mathrm{N} 150} / \rho_{\mathrm{N} 60} \simeq 10$ between 30 and $80 \mathrm{~km}$ in depth. This is equivalent to the one obtained by Kellet et al. $(1992 \mathrm{~b})\left(\rho_{\mathrm{NS}} / \rho_{\mathrm{EW}} \simeq 10 ; 30-100 \mathrm{~km}\right)$ and by Tournerie and Chouteau (1998) $\left(\rho_{\mathrm{NS}} / \rho_{\mathrm{EW}} \simeq 30 ; 40\right.$ $100 \mathrm{~km}$ ). Hypotheses to explain this mantle anisotropy has been previously discussed by Kellet et al. (1992b) and by Mareschal et al. (1995). They suggest that such anisotropy could result from precipitation of thin films of graphite from $\mathrm{CO}_{2}$-rich fluid, now aligned along the EW axes. In this study, data quality for the longest periods $(T>500 \mathrm{~s})$, the relative low limit $T<5000 \mathrm{~s}$, and the rotation of the $\mathrm{N} 90^{\circ}$ impedances along the $\mathrm{N} 60^{\circ}$ direction clearly limit the resolution of the deeper part of the MT model and diseable precise analysis of this anisotropy.

Lack of a significant vertical magnetic transfer func- tion suggests that electrical anisotropy is the cause of the observed apparent anisotropy of the resistivity sounding curves. The difference of strike direction between the short and long periods $\left(\mathrm{N} 60^{\circ}\right.$ and $\left.\mathrm{N} 90^{\circ}\right)$ also suggest that upper crust and upper mantle anisotropy are not parallel.

\section{Conclusion}

Study of the magnetotelluric data collected along the Lithoprobe seismic line 21 indicates a thickening from the East to the West of the BRG. This result is in agreement with the results obtained by the analysis of the seismic line 21 and the gravity data. The analysis also shows the presence of resistivity anisotropy in the upper crust and upper mantle of the BRG. This hypothesis of anisotropy might be considered in old and complex area such as the Archean Abitibi Greenstone Belt.

The resolution of the MT method in the highly resistive environment is poor and a precise image near the $\mathrm{HuCF}$ cannot be obtained. Nevertheless, one can note that the infered thickening of the BRG seems to occur in its vicinity. In order to increase the resolution, one solution might be to collect more AMT/MT data along the entire profile to fill up gaps between several sites and in the western part of the profile close to the Hunter Creek fault to increase the lateral resolution.

Acknowledgments. This research was supported by NSERC grant OGP000848 and FCAR team grant. The authors also like to acknowledge the financial support of Falconbridge Ltd and Phoenix Geophysics. We would like to thank Ping Zhang, Bernard Giroux and Stefka Krivochieva for their unconditional help in field work. Authors would like to thank both reviewers (Ian Ferguson and Juanjo Ledo) for helpful comments that improved the final manuscript. Lithoprobe contribution \#1246.

\section{Appendix A. Relationship between Magnetic Transfer Functions and GIC's}

Geomagnetically induced currents (GIC) flowing in the neutral of power lines are caused by potential differences existing between two grounding sites (Fig. A.1). The voltage drop $\Delta V$ between the two groundings is given by:

$$
\Delta V=\int_{L} \vec{E} \cdot \vec{d} l=E_{x} L
$$

If $R$ is the total resistance of the neutral wire and grounding electrodes, the current $I$ flowing in the wire is $I=$ $\Delta V / R=E_{x} L / R$ where $E_{x}=Z_{x y} H_{y}$.

At large distance from the power line $(r \gg h)$, the magnetic field generated by $I$ has a vertical component $H_{z}(r)=$ $I /(2 \pi r)$ assuming the current line to be infinite. If the horinzontal magnetic field $H_{y}(r)$ does not varie over the distance $r$, the magnetic transfer function $H_{z} / H_{y}$ can be expressed as:

$$
\begin{aligned}
T_{z y}(r) & =\frac{H_{z}(r)}{H_{y}(r)} \simeq \frac{H_{z}(r)}{H_{y}(0)}=\left(\frac{L}{2 \pi R r}\right) \cdot \frac{E_{x}(0)}{H_{y}(0)} \\
& \simeq\left(\frac{L}{2 \pi R r}\right) \cdot Z_{x y}(0)
\end{aligned}
$$

Therefore, for a constant geometry the magnitude of $T_{z y}$ is proportional to the magnitude of MT impedance $Z_{x y}$. $T_{z y}$ decreases as $1 / r$ as the recording site is moved away from 


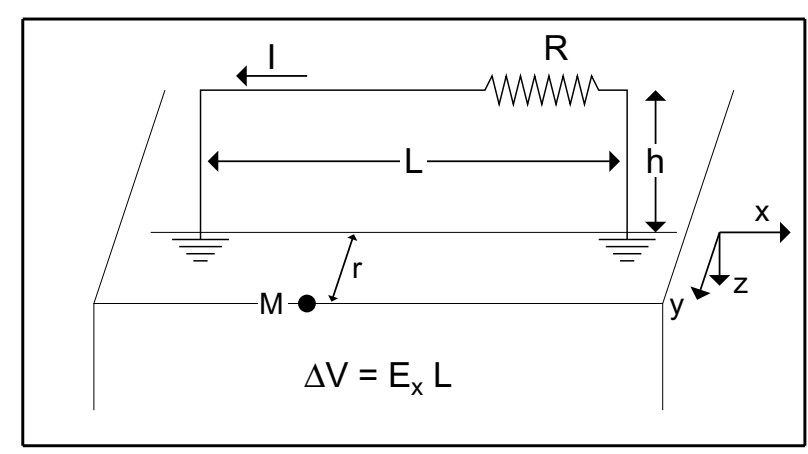

Fig. A.1. Schematic electrical circuit of GIC's.

the powerline. Its phase will be the same as $Z_{x y}$. In practice, the neutral wire and groundings are not purely resistive $(R$ may have a reactive component) and some phase difference may occur.

The simple development here (1) neglects the interaction of the magnetic vertical field with the conductivity distribution below the recording site; (2) assumes that the earth is $1 \mathrm{D}$ isotropic or anisotropic.

\section{References}

Adam, E., B. Milkereit, M. Mareschal, A. E. Barnes, C. Hubert, and M. Salisbury, The application of reflection seismology to the investigation of the geometry of near-surface units and faults in the Blake River Group, Abitibi belt, Quebec, Canadian Journal of Earth Sciences, 29, 20382045, 1992.

Bahr, K., Interpretation of the magnetotelluric impedance tensor: regional induction and local telluric distortion, J. Geophys., 62, 119-127, 1988.

Bahr, K., Geologic noise in magnetotelluric data: a classification of distortion types, Phys. Earth Planet. Inter, 66, 24-38, 1991.

Bellefleur, G., Contribution of potential methods to the geological and the deep structure cartography in the Blake River Group, Abitibi, Master's thesis, École Polytechnique de Montréal, 101 pp., 1992 (in French).

Bitri, A., J. P. Brun, J. Chantraine, P. Guennoc, G. Marquis, J. M. Marthelot, J. Perrin, F. Pivot, B. Tournerie, and C. Truffert, Crustal structure of the Cadomian block in the north Brittany (France): seismic reflection and magnetotelluric sounding (Geofrance 3D-Armor project), Comptes Rendus de l'Académie des Sciences de Paris, 325, 171-177, 1997 (in French).

Camiré, G. and D. H. Watkinson, Volcanic stratigraphy and structure in the Hunter-Creek fault area, Rouyn-Noranda, Quebec, Canadian Journal of Earth Sciences, 27, 1348-1358, 1990.

Chakridi, R., Magnetotelluric interpretation in complex environments, Ph.D. thesis, École Polytechnique de Montréal, 253 pp., 1991 (in French).

Chown, E. H., R. Daigneault, and W. Mueller, Tectonic evolution of the Northern Volcanic Zone, Abitibi belt, Quebec, Canadian Journal of Earth Sciences, 29, 2211-2225, 1992.

Clowes, R. M., A. J. Calvert, D. W. Eaton, Z. Hajnal, J. Hall, and G. M. Ross, Lithoprobe reflection studies of Archean and Proterozoic crust in Canada, Tectonophys., 264, 65-88, 1996.

Cook, F. A. and A. G. Jones, Seismic reflections and electrical conductivity: A case of Holmes' curious dog?, Geology, 23, 141-144, 1995.

Deschamps, F., M. Chouteau, and D. J. Dion, Geological interpretation of aeromagnetic and gravimetric data in the region located at the west part of the Rouyn-Noranda city, in Études géophysiques récentes de certains secteurs de la ceinture volcanosédimentaire de l'Abitibi, edited by D.-J. Dion, Ministère des Ressources Naturelles, Québec, DV-93-10, 55 pp., 1993 (in French).

Dumas, I., Interpretation of line 21 seismic reflection data, Blake River Group, Abitibi (Canada), Master's thesis, École Polytechnique de Montréal, 111 pp., 1995 (in French).

Eisel, M. and K. Bahr, Electrical anisotropy in the lower crust of British Columbia: an interpretation of a magnetotelluric profile after tensor decomposition, J. Geomag. Geoelectr., 45, 1115-1126, 1993.
Gamble, T. D., W. M. Goubau, and J. Clarke, Magnetotellurics with a remote magnetic reference, Geophysics, 44, 53-68, 1979.

Gough, D. I., Seismic reflectors, conductivity, water and stress in the continental crust, Nature, 323, 143-144, 1986.

Green, A. G., B. Milkereit, L. J. Mayrand, J. N. Ludden, C. Hubert, S. J. Jackson, R. H. Sutcliffe, G. F. West, P. Verpaelst, and A. Simard, Deep structure of an Archean greenstone terrane, Nature, 344, 327-330, 1990.

Groom, R. W. and R. C. Bailey, Decomposition of magnetotelluric impedance tensors in the presence of local three-dimensional galvanic distortion, J. Geophys. Res., 94, 1913-1925, 1989.

Groom, R. W., R. D. Kurtz, A. G. Jones, and D. E. Boerner, A quantitative methodology to extract regional magnetotelluric impedances and determine the dimension of the conductivity structure, Geophysical Journal International, 115, 1095-1118, 1993.

Hobbs, B. A., Terminology and symbols for use in studies of electromagnetic induction in the Earth, Surveys in Geophysics, 13, 489-515, 1992.

Hubert, C., P. Trudel, and L. Gelinas, Archean wrench fault tectonics and structural evolution of the Blake River Group, Abitibi belt, Quebec, Canadian Journal of Earth Sciences, 21, 1024-1032, 1984.

Jackson, S. L. and A. R. Cruden, Formation of the Abitibi greenstone belt by arc-trench migration, Geology, 23, 471-474, 1995.

Jackson, S. L., R. H. Sutcliffe, J. N. Ludden, C. Hubert, A. G. Green, B. Milkereit, L. J. Mayrand, G. F. West, and P. Verpaelst, Southern Abitibi greenstone belt: Archean crustal structure from seismic-reflection profiles, Geology, 18, 1086-1090, 1990.

Jones, A. G., MT and reflection: an essential combination, Geophys. J. Roy. Astr. Soc., 89, 7-18, 1987.

Jones, A. G., Static shift of magnetotelluric data and its removal in sedimentary basin environment, Geophysics, 53, 967-978, 1988.

Jones, A. G. and R. W. Groom, Strike-angle determination from the magnetotelluric impedance tensor in the presence of noise and local distortion: Rotate at your peril!, Geophysical Journal International, 113, 524-534, 1993.

Jones, A. G., R. W. Groom, and R. D. Kurtz, Decomposition and modelling of the BC87 dataset J. Geomag. Geoelectr., 45, 1127-1150, 1993.

Kellett, R. L., M. Chouteau, R. D. Kurtz, and M. Mareschal, A magnetotelluric transect from the Grenville to the Northern Abitibi, Lithoprobe Report, 25, 55-58, 1992a.

Kellett, R. L., M. Mareschal, and R. D. Kurtz, A model of lower crustal electrical anisotropy for the Pontiac Subprovince of the Canadian Shield, Geophysical Journal International, 111, 141-150, $1992 \mathrm{~b}$.

Kellett, R. L., A. E. Barnes, and M. Rive, The deep structure of the Grenville Front: a new perspective from western Quebec, Canadian Journal of Earth Sciences, 31, 282-292, 1994.

Kurtz, R. D., M. Mareschal, F. Richard, R. L. Kellett, and R. Bailey, Crustal structure from magnetotelluric soundings along a profile from the Kapuskasing zone to the Pontiac Subprovince, Lithoprobe Report, 25, 59-63, 1992.

Kurtz, R. D., J. A. Craven, E. R. Niblett, and R. A. Stevens, The conductivity of the crust and mantle beneath the Kapuskasing Uplift: electrical anisotropy in the upper mantle, Geophysical Journal International, 113, 483-498, 1993.

Ludden, J. N., C. Hubert, and C. Gariépy, The tectonic evolution of the Abitibi greenstone belt of Canada, Geological Magazine, 123, 153-166, 1986.

Mareschal, M., R. L. Kellett, R. D. Kurtz, J. N. Ludden, S. Ji, and R. C. Bailey, Archean cratonic roots, mantle shear zones and deep electrical anisotropy, Nature, 375, 134-137, 1995.

Marquis, G., A. Jones, and R. D. Hyndman, Coincident conductive and reflective middle and lower crust in southern British Columbia, Geophysical Journal International, 120, 111-131, 1995.

MRN, Airborne EM survey using INPUT MK VI, Noranda region, Relevés Géophysiques inc. Ministère des Ressources Naturelles, Québec, DP86-17, 1986 (in French).

Pek, J. and T. Verner, Finite difference modelling of magnetotelluric fields in 2-D anisotropic media, Geophysical Journal International, 128, 505521, 1997.

Perron, G. and A. J. Calvert, Shallow, high-resolution seismic imaging at the Ansil mining camp in the Abitibi greenstone belt, Geophysics, 63, 379-391, 1998.

Singer, B. S., Correction for distortions of magnetotelluric fields: Limits of validity of the static approach, Surveys in Geophysics, 13, 309-340, 1992.

Smith, J. T., Understanding telluric distortion matrices, Geophysical Journal International, 122, 219-226, 1995. 
Smith, J. T. and J. R. Booker, Rapid inversion of two- and three-dimensional magnetotelluric data, J. Geophys. Res., 96, 3905-3922, 1991.

Tournerie, B. and M. Chouteau, Deep conductivity structure in Abitibi using long dipole magnetotelluric measurements, Geophys. Res. Lett., 25, 2317-2320, 1998.

Verpaelst, P., A. S. Peloquin, E. Adam, A. E. Barnes, J. N. Ludden, D. J. Dion, C. Hubert, B. Milkereit, and M. Labrie, Seismic reflection profiles across the "Mine Series" in the Noranda Camp of the Abitibi belt, eastern Canada, Canadian Journal of Earth Sciences, 32, 167-176, 1995.

Zhang, P., L. B. Pedersen, M. Mareschal, and M. Chouteau, Channeling contribution to tipper vectors: a magnetic equivalent to electrical distortion, Geophysical Journal International, 113, 693-700, 1993.

Zhang, P., M. Chouteau, M. Mareschal, R. Kurtz, and C. Hubert, Highfrequency magnetotelluric investigation of crustal structure in northern central Abitibi, Quebec, Canada, Geophysical Journal International, 120, 406-418, 1995.

B. Tournerie (e-mail: tourneri@geo.polymtl.ca) and M. Chouteau 